\title{
Breast cancer in women aged 75 years and older - fumour characteristics and treatment options
}

\author{
Piotr Kędzierawski ${ }^{1,2}$, Ryszard Mężyk ${ }^{3}$ \\ ${ }^{1}$ Collegium Medicum, Jan Kochanowski University, Kielce, Poland \\ ${ }^{2}$ Breast Cancer Unit, The Holycross Cancer Centre, Kielce, Poland \\ ${ }^{3}$ Department of Epidemiology and Cancer Control, The Holycross Cancer Centre, Kielce, Poland
}

\begin{abstract}
Introduction: An optimal approach to older women with breast cancer is still a major challenge. In this paper, we present a retrospective analysis of treatment in patients aged 75 years and older who were treated at the Holycross Cancer Centre in 2015-2019.

Material and methods: The analysed group consisted of 259 women. For estimation of the general status of patients, we used the Geriatric 8 questionnaire. For every patient, an individual treatment plan was established. Survival analysis was performed; disease-free survival (DFS), cancer-specific survival, and overall survival (OS) were calculated by the Kaplan-Meier method. For DFS and OS, the Cox proportional-hazard regression was applied.

Results: The mean age in the analysed group was 80 years. Stage I and II cancer accounted for over $80 \%$ of patients. Radical mastectomy was performed in $56 \%$ and breast-conserving surgery in over $34 \%$ of patients. Sentinel lymph node biopsy was used in 114 patients. Preoperative systemic treatment was applied in 34 and postoperative chemotherapy in 51 patients, respectively. Trastuzumab was used in 23 patients. Postoperative hormonal therapy was applied in 205 and radiotherapy in 178 patients. During the observation after the treatment 32 patients died, while 227 survived. In multivariate analysis for DFS hormonotherapy was statistically significant for OS clinical stage and hormonotherapy.

Conclusions: The treatment plan for older women consisted of surgery and radiation therapy, and systemic treatment should be always considered. The decision should be made by the breast cancer team.
\end{abstract}

Key words: breast cancer, surgery, radiotherapy, systemic treatment.

\section{Introduction}

Breast cancer $(\mathrm{BC})$ is the most common malignancy diagnosed in women. The incidence of BC increases with age. Schedules of treatment are very well established for women in good status, but quite often patients over 75 years of age are not treated as recommended, mainly due to poor general conditions and comorbidities, despite the diagnosis of cancer at the stage of local or locoregional advancement [1-5]. However, when analysing data from the literature, and based on our own experience, it is always necessary to consider the treatment of older women despite some concerns and relative contraindications [6]. Since 2012, when the Holycross Cancer Centre (HCC) in Kielce was preparing for the Senologic International Society (SIS) certification, and particularly after receiving it in 2015, every patient with $B C$ who reports to the hospital is diagnosed, and individual treatment is determined for each patient. In this paper, we present the retrospective analysis on treatment in patients aged 75 years and older who were treated at the HCC in 2015-2019.

\section{Material and methods}

The danalysed group consisted of 259 women with non-disseminated BC qualified for radical treatment. For the estimation of the general status of patients, we used the G8 (Geriatric8) questionnaire. Particularly before the start of the systemic treatment, this scale was the most useful. In patients with less than 14 points, as recommended, we were very cautious about starting with chemotherapy. For every patient, an individual treatment plan was established according to the general condition, the presence of comorbidities, the stage of cancer, and of course the biological subtype of cancer. Due to the risk of cardiovascular complications in this group of patients, each patient qualified for systemic treatment (chemotherapy and trastuzumab treatment) was consulted by a cardiologist before treatment and also during systemic treatment. The mean observation time after the treatment was 29 months, and 12 women were observed for longer than 5 years. The characteristics of the patients are presented in Table 1. We did not ask for the approval of the Ethics Committee due to the 
Table 1. Characteristics of the group

\begin{tabular}{|c|c|c|c|c|c|}
\hline & Factor & Total & $<80$ years & $\leq 80$ years & $p$-value \\
\hline 1 & Number of patients & 259 & $138(53.3 \%)$ & $121(46.7 \%)$ & \\
\hline \multirow[t]{4}{*}{2} & Age & & & & \multirow{4}{*}{-} \\
\hline & Mean i Median & $75-92$ & $75-79$ & $80-92$ & \\
\hline & Mean (SD) & $80(3.8)$ & $77.1(1.4)$ & $83.3(2.9)$ & \\
\hline & Median (Q1-Q3) & $79(77-82)$ & $77(76-78)$ & $83(81-85)$ & \\
\hline \multirow[t]{5}{*}{3} & Type of cancer & & & & \multirow{5}{*}{0.1320} \\
\hline & Lobular cancer & $30(11.6 \%)$ & $22(73.3 \%)$ & $8(26.7 \%)$ & \\
\hline & No special type of cancer & $197(76.1 \%)$ & $99(50.3 \%)$ & $98(49.7 \%)$ & \\
\hline & Ductal cancer in situ & $8(3.1 \%)$ & $4(50.0 \%)$ & $4(50.0 \%)$ & \\
\hline & Other & $24(9.3 \%)$ & $13(54.2 \%)$ & $11(45.8 \%)$ & \\
\hline \multirow[t]{5}{*}{4} & Subtype of cancer & & & & \multirow{5}{*}{0.8458} \\
\hline & Luminal A & $1.7(50.6 \%)$ & $66(52.0 \%)$ & $61(48.0 \%)$ & \\
\hline & Luminal B & $77(30.7 \%)$ & $44(57.1 \%)$ & $33(42.9 \%)$ & \\
\hline & Triple-negative & $34(13.5 \%)$ & $18(52.9 \%)$ & $16(47.1 \%)$ & \\
\hline & Non-luminal & $13(5.2 \%)$ & $6(46.2 \%)$ & $7(53.8 \%)$ & \\
\hline \multirow[t]{4}{*}{5} & Grading & & & & \multirow{4}{*}{0.9247} \\
\hline & G1 & $98(37.8 \%)$ & $52(53.1 \%)$ & $46(46.9 \%)$ & \\
\hline & $\mathrm{G} 2$ & $125(48.3 \%)$ & $67(53.6 \%)$ & $58(47.9 \%)$ & \\
\hline & G3 & 36 (13.9\%) & $19(52.8 \%)$ & $17(47.2 \%)$ & \\
\hline \multicolumn{5}{|c|}{6 a Ki-67 factor } & \multirow{4}{*}{0.7727} \\
\hline & Min-max & 0-95 & $0-90$ & $0-95$ & \\
\hline & Mean (SD) & $21(25.1)$ & $21(24.7)$ & $21(25.8)$ & \\
\hline & Median (Q1-Q3) & $10(5-30)$ & $10(3-30)$ & $10(5-30)$ & \\
\hline \multicolumn{5}{|c|}{6 b Ki-67 factor } & \multirow{3}{*}{0.2908} \\
\hline & $\leq 21$ & $184(71.0 \%)$ & $102(55.4 \%)$ & $82(44.6 \%)$ & \\
\hline & $>21$ & $75(29.0 \%)$ & $36(48.0 \%)$ & $39(52.0 \%)$ & \\
\hline \multirow[t]{5}{*}{7} & Clinical stage & & & & \multirow{5}{*}{0.9318} \\
\hline & 0 & $8(3.1 \%)$ & $4(50.0 \%)$ & $4(50.0 \%)$ & \\
\hline & 1 & $46(17.8 \%)$ & $25(54.3 \%)$ & $21(45.7 \%)$ & \\
\hline & II & $166(64.0 \%)$ & $90(54.2 \%)$ & $76(45.8 \%)$ & \\
\hline & III & $39(15.1 \%)$ & $19(48.7 \%)$ & $20(51.3 \%)$ & \\
\hline \multirow[t]{4}{*}{8} & Surgery type & & & & \\
\hline & Breast-conserving treatment & $87(33.6 \%)$ & $51(58.6 \%)$ & $36(41.4 \%)$ & \multirow{3}{*}{0.2910} \\
\hline & Radical mastectomy & $145(56.0 \%)$ & $71(49.0 \%)$ & $74(51.0 \%)$ & \\
\hline & Simple mastectomy & $27(10.4 \%)$ & $16(59.3 \%)$ & $11(40.7 \%)$ & \\
\hline \multirow[t]{3}{*}{9} & Sentinel lymph node biopsy & & & & \\
\hline & No & $145(56.0 \%)$ & $71(49.0 \%)$ & $74(51.0 \%)$ & \multirow{2}{*}{0.1171} \\
\hline & Yes & $114(44.0 \%)$ & $67(58.8 \%)$ & $47(41.2 \%)$ & \\
\hline \multirow[t]{3}{*}{10} & Axillary dissection & & & & \multirow{3}{*}{0.1816} \\
\hline & No & $112(43.2 \%)$ & $65(58.0 \%)$ & $47(42.0 \%)$ & \\
\hline & Yes & $147(56.8 \%)$ & $73(49.7 \%)$ & $74(50.3 \%)$ & \\
\hline \multirow[t]{5}{*}{11} & Pathological clinical stage & & & & \multirow{5}{*}{0.8054} \\
\hline & $\underline{0}$ & $14(5.4 \%)$ & $9(64.3 \%)$ & $5(35.7 \%)$ & \\
\hline & 1 & 39 (15.1\%) & $20(51.3 \%)$ & 19 (48.7\%) & \\
\hline & 2 & $154(59.5 \%)$ & 80 (51.9\%) & 74 (48.1\%) & \\
\hline & 3 & $52(20.1 \%)$ & $29(55.8 \%)$ & $23(44.2 \%)$ & \\
\hline
\end{tabular}


Table 1. Cont.

\begin{tabular}{|c|c|c|c|c|c|}
\hline & Factor & Total & $<80$ years & $\leq 80$ years & $p$-value \\
\hline \multirow[t]{6}{*}{12} & Preoperative systemic treatment & & & & \multirow{3}{*}{0.9660} \\
\hline & No & $225(86.9 \%)$ & $120(53.3 \%)$ & $105(46.7 \%)$ & \\
\hline & Yes & $34(13.2 \%)$ & $18(52.9 \%)$ & $16(47.1 \%)$ & \\
\hline & \multicolumn{4}{|l|}{ For "Yes" included: } & \multirow{3}{*}{0.4538} \\
\hline & Chemotherapy & $25(73.5 \%)$ & $14(56.0 \%)$ & $11(44.0 \%)$ & \\
\hline & Hormonotherapy & $9(26.5 \%)$ & $4(44.4 \%)$ & $5(55.6 \%)$ & \\
\hline \multirow[t]{6}{*}{13} & Postoperative systemic treatment & & & & \multirow{3}{*}{0.0001} \\
\hline & No & $208(80.3 \%)$ & $98(47.1 \%)$ & $110(52.9 \%)$ & \\
\hline & Yes & $51(19.7 \%)$ & $40(78.4 \%)$ & $11(21.6 \%)$ & \\
\hline & \multicolumn{4}{|l|}{ For "Yes" included: } & \multirow{3}{*}{0.4538} \\
\hline & Chemotherapy & 49 (96.1\%) & $38(77.6 \%)$ & $11(22.4 \%)$ & \\
\hline & Chemotherapy with Capecitabine & $2(3.9 \%)$ & $2(100.0 \%)$ & $0(0 \%)$ & \\
\hline \multirow[t]{3}{*}{14} & Postoperative hormonotherapy & & & & \multirow{3}{*}{0.8132} \\
\hline & No & $54(20.8 \%)$ & $28(51.9 \%)$ & $26(48.1 \%)$ & \\
\hline & Yes & $205(79.2 \%)$ & $110(53.7 \%)$ & $95(46.3 \%)$ & \\
\hline \multirow[t]{3}{*}{15} & AntiHER2 therapy & & & & \multirow{3}{*}{0.2303} \\
\hline & No & $236(91.1 \%)$ & $123(52.1 \%)$ & $113(47.9 \%)$ & \\
\hline & Yes & $23(8.9 \%)$ & $15(65.2 \%)$ & $8(34.8 \%)$ & \\
\hline \multirow[t]{3}{*}{16} & Radiotherapy & & & & \multirow{3}{*}{0.0550} \\
\hline & No & $81(31.3 \%)$ & $36(44.4 \%)$ & $45(55.6 \%)$ & \\
\hline & Yes & $178(68.7 \%)$ & $102(57.3 \%)$ & $76(42.7 \%)$ & \\
\hline \multirow[t]{3}{*}{17} & Status of live & & & & \multirow{3}{*}{0.4387} \\
\hline & Alive & $227(87.6 \%)$ & $123(54.2 \%)$ & $104(45.8 \%)$ & \\
\hline & Dead & $32(12.4 \%)$ & $15(46.9 \%)$ & $17(53.1 \%)$ & \\
\hline \multirow[t]{3}{*}{18} & Death because of cancer & & & & \multirow{3}{*}{0.5893} \\
\hline & No & $250(96.5 \%)$ & $134(53.6 \%)$ & $116(46.4 \%)$ & \\
\hline & Yes & $9(3.5 \%)$ & $4(44.4 \%)$ & $5(55.6 \%)$ & \\
\hline \multirow[t]{3}{*}{19} & Death because of other reasons & & & & \multirow{3}{*}{0.5835} \\
\hline & No & $236(91.1 \%)$ & $127(53.8 \%)$ & $109(46.2 \%)$ & \\
\hline & Yes & $23(8.9 \%)$ & $11(47 \%)$ & $12(52 \%)$ & \\
\hline \multirow[t]{3}{*}{20} & Recurrence & & & & \multirow{3}{*}{0.5893} \\
\hline & No & $250(96.5 \%)$ & $134(53.6 \%)$ & $116(46.4 \%)$ & \\
\hline & Yes & $9(3.5 \%)$ & $4(44.4 \%)$ & $5(55.6 \%)$ & \\
\hline \multirow[t]{4}{*}{21} & Overall survival & & & & \multirow{4}{*}{0.0178} \\
\hline & Min-max & $0.27-66.1$ & $0.27-64.1$ & $0,87-66,1$ & \\
\hline & Mean (SD) & $28.7(18.4)$ & $31.3(18.7)$ & $25.7(17.6)$ & \\
\hline & Median (Q1-Q3) & $25.9(12.3-44.7)$ & $31.0(14.0-48.7)$ & $22.1(11.3-40.1)$ & \\
\hline \multirow[t]{4}{*}{22} & Disease free survival & & & & \\
\hline & Min-max & $0.27-66.1$ & $0.27-64.1$ & $0.87-66.1$ & 00134 \\
\hline & Mean (SD) & $28.6(18.5)$ & $31.2(18.8)$ & $25.6(17.7)$ & \\
\hline & Median (Q1-Q3) & $25.9(12.2-44.7)$ & $31.0(13.8-48.7)$ & $20.9(11.3-40.1)$ & \\
\hline
\end{tabular}


retrospective nature of the analysis. Upon admission to hospital, the written consent of the patients to be included in the study was obtained.

\section{Statistical analysis}

The following measures, tests, and methods of statistical analysis were used in the work:

1. Basic statistical measures (mean, standard deviation, median, quartiles, minimum, maximum) for continuous features as well as frequencies and percentages for qualitative and ordinal features.

2. $\chi^{2}$ test to assess the significance of differentiation in single classifications and to assess the correlation of pairs of features in double classifications.

3. Mann-Whitney test for features to examine the differentiation of a feature in the two groups studied.

4. Survival analysis was performed: for disease-free survival (DFS), cancer-specific survival (CSS), overall survival (OS), and survival proportions for time points (12, 24, 36, 48, 60 months) was calculated by Kaplan-Meier method. For disease-free survival and OS the Cox proportional-hazard regression (univariate and multivariate) was applied - hazard ratios with 95\% confidence interval, and the $p$-value was calculated. The FORWARD procedure was used as a method of selecting variables for the multivariate Cox regression model. It was assumed that $p$-values less than 0.05 indicate statistical significance. Statistical analyses were performed using MedCalc Statistical Software version 19.1 (MedCalc Software bv, Ostend, Belgium; https://www.medcalc.org; 2020).

\section{Results}

The characteristics of the group are presented in Table 1 . The mean age in the analysed group was 80 years.
No special type of cancer was most often recognized in this group (76\%). Only 8 patients were diagnosed with pre-invasive cancer. Luminal A cancer was diagnosed in 127 women. Patients with stage I and II cancer accounted for over $80 \%$ of the total number of analysed patients. Radical mastectomy (RM) was performed in 145 (56\%) women, but breast-conserving surgery (BCS) was performed in over 80 patients (34\%). Sentinel lymph node biopsy (SLNB) was performed in 114 (44\%) patients who were treated with breast-conserving surgery, but also with a simple mastectomy (SM). Preoperative systemic treatment was used in 34 patients, including 25 with chemotherapy (in triple-negative and non-luminal subtypes) and 9 with hormonotherapy (in luminal subtypes). In 6 patients pathological complete response was achieved after neoadjuvant systemic therapy, in 4 of them HER2 overexpression, and in 1 a triple-negative subtype of cancer was recognized. One patient achieved pCR after neoadjuvant hormonotherapy. Postoperative chemotherapy received 51 (20\%) patients. Two patients with triple-negative cancer, who did not achieve pCR after neoadjuvant chemotherapy, received adjuvant capecitabine. Schedules of chemotherapy most often used were as follows: 4 cycles of Adriamycin (A) or Epirubicin (E) with Cyclophosphamide (C) followed by 12 cycles Paclitaxel (P) and 4 or 6 cycles of AC or EC. Treatment with trastuzumab was used in 23 patients. Postoperative hormone therapy (HT) was used in 205 (79\%) patients and radiotherapy in 178 (69\%) patients. Hormonotherapy was used in $100 \%$ of patients with luminal subtypes. Similarly, adjuvant, conformal radiotherapy was applied in $100 \%$ of in women in whom BCS was performed. Radiotherapy was hypofractionated - 2.5 Gy per fraction to 42.5 Gy with a boost in 4 fractions in BCS patients and 2.25 Gy per fraction to $45 \mathrm{~Gy}$ for women after mastectomy. The treatment connected with the subtype of cancer is presented in Table 2.

Table 2. Treatment according to the biological subtype of cancer

\begin{tabular}{|c|c|c|c|c|c|c|}
\hline $\begin{array}{l}\text { Subtype } \\
\text { of cancer }\end{array}$ & $\begin{array}{l}\text { Number } \\
\text { of patients }\end{array}$ & Surgery & $\begin{array}{l}\text { Neoadjuvant } \\
\text { CHTH/HTH }\end{array}$ & $\begin{array}{l}\text { Adjuvant } \\
\text { CHTH/HTH }\end{array}$ & $\begin{array}{c}\text { AntiHER2 } \\
\text { therapy }\end{array}$ & Radiotherapy \\
\hline $\begin{array}{l}\text { Ductal cancer } \\
\text { in situ }\end{array}$ & 8 & $\begin{array}{l}\text { BCS-7 (87\%) } \\
\text { RM-0 } \\
\text { SM-1 (13\%) }\end{array}$ & $\begin{array}{l}\text { CHTH-O } \\
\text { HTH-O }\end{array}$ & $\begin{array}{c}\text { CHTH-0 } \\
\text { HTH-4 (50\%) }\end{array}$ & 0 & After BCS-7 (100\%) \\
\hline Luminal A & 127 & $\begin{array}{c}\text { BCS-53 (42\%) } \\
\text { RM-62 (49\%) } \\
\text { SM-12 (9\%) }\end{array}$ & $\begin{array}{c}\text { CHTH-2 (2\%) } \\
\text { HTH-4 (3\%) }\end{array}$ & $\begin{array}{c}\text { CHTH-3 (2\%) } \\
\text { HTH-127 (100\%) }\end{array}$ & 0 & $\begin{array}{c}\text { After BCS-53 (100\%) } \\
\text { After RM-35 (56\%) } \\
\text { After SM-3 (25\%) }\end{array}$ \\
\hline Luminal B & 58 & $\begin{array}{l}\text { BCS-14 (24\%) } \\
\text { RM-34 (57\%) } \\
\text { SM-10 (17\%) }\end{array}$ & $\begin{array}{c}\text { CHTH-7 (12\%) } \\
\text { HTH-4 (7\%) }\end{array}$ & $\begin{array}{l}\text { CHTH-15 (26\%) } \\
\text { HTH-58 (100\%) }\end{array}$ & 0 & $\begin{array}{c}\text { After BCS-14 (100\%) } \\
\text { After RM-19 (56\%) } \\
\text { After SM-4 (40\%) }\end{array}$ \\
\hline $\begin{array}{l}\text { Luminal B } \\
\text { HER2 positive }\end{array}$ & 19 & $\begin{array}{c}\text { BCS-7 (37\%) } \\
\text { RM-11 (58\%) } \\
\text { SM-1 (5\%) }\end{array}$ & $\begin{array}{c}\text { CHTH-4 (21\%) } \\
\text { HTH-1 (5\%) }\end{array}$ & $\begin{array}{c}\text { CHTH-10 (53\%) } \\
\text { HTH-16 (84\%) }\end{array}$ & $17(89 \%)$ & $\begin{array}{c}\text { After BCS-7 (100\%) } \\
\text { After RM-8 (73\%) } \\
\text { After SM-0 (0\%) }\end{array}$ \\
\hline $\begin{array}{l}\text { Triple- } \\
\text { negative }\end{array}$ & 34 & $\begin{array}{l}\text { BCS-5 (15\%) } \\
\text { RM-25 (74\%) } \\
\text { SM-4 (12\%) }\end{array}$ & CHTH-9 (26\%) & CHTH-18 (53\%) & 0 & $\begin{array}{c}\text { After BCS-5 (100\%) } \\
\text { After RM-14 (56\%) } \\
\text { After SM-1 (25\%) }\end{array}$ \\
\hline Non-luminal & 13 & $\begin{array}{c}\text { BCS-1 (8\%) } \\
\text { RM-12 (92\%) } \\
\text { SM-0 }\end{array}$ & CHTH-3 (23\%) & CHTH-5 (38\%) & $6(46 \%)$ & $\begin{array}{c}\text { After BCS-1 (100\%) } \\
\text { After RM-8 (67\%) } \\
\text { After SM-0 (0\%) }\end{array}$ \\
\hline
\end{tabular}


Table 3. Survival probability analysis

\begin{tabular}{lccc}
\hline \multirow{2}{*}{ Months } & \multicolumn{3}{c}{ Survival probability (\%) } \\
\cline { 2 - 4 } & Disease-free survival & Cancer-specific survival & Overall survival \\
\hline 12 & $98.3(0.1)$ & $98.7(0.7)$ & $94.7(1.5)$ \\
\hline 24 & $96.5(1.2)$ & $96.8(1.3)$ & $90.1(2.1)$ \\
\hline 36 & $94.8(1.8)$ & $95.3(1.7)$ & $85.6(2.7)$ \\
\hline 48 & $94.8(1.8)$ & $94.3(1.9)$ & $83.4(3.1)$ \\
\hline 60 & $94.8(1.8)$ & $94.3(1.9)$ & $74.5(5.2)$ \\
\hline Number of events (\%) & $9(3.5)$ & $9(3.5)$ & $32(12.4)$ \\
\hline Number of censored (\%) & $250(96.5)$ & $250(96.5)$ & $227(87.6)$ \\
\hline Mean survival (95\% PU) & $63.6(62.0-65.2)$ & $63.5(61.9-65.2)$ & $57.4(54.7-60.2)$ \\
\hline
\end{tabular}

During the observation after the treatment (mean 29 months) 32 patients died, while 227 survived alive. Nine died from disseminated $B C$ and 23 died from other causes without evidence of recurrence. Only 12 women (5\%) from this group had undergone only surgery without adjuvant treatment. Nine of them survived and 3 died. The probability of both DFS and OS was higher in women aged 80 years and younger (Table 1 ). The 5 -year probability of DFS for the entire group is $94.8 \%$. The 5 -year probability of CSS is much higher than the overall survival. Deaths for reasons other than cancer were much more frequent and in the analysed group (Table 3). In univariate Cox proportional-hazard regression, which is presented in Table 4, many factors were statistically important for DFS and OS. In multivariate analysis with FORWARD method for DFS statistically significant was hormonotherapy $(\mathrm{HR}=0.1 ; 95 \% \mathrm{Cl}[0.01-0.2]$; $p$-value = $0.0001)$, for OS clinical stage $(\mathrm{HR}=2.9 ; 95 \% \mathrm{Cl}[1.6-5.5]$; $p$-value $=0.0006)$, and hormonotherapy $(\mathrm{HR}=0.3 ; 95 \%$ $\mathrm{Cl}[0.1-0.6] ; p$-value $=0.0006)$.

\section{Discussion}

An optimal approach to older women with $B C$ is still a major challenge. For older patients with early-stage breast cancer, the standards of care often are not strictly followed due to either clinician biases or patient preferences [6]. Older patients with BC are also significantly under-represented in clinical trials [7]. Biological age, comorbidity, and functional status are important factors to be considered in treatment decisions in older cancer patients. In general, advancing age is associated with reduced tolerance to physiological stress, higher prevalence of comorbidity, reduced social support, and cognitive impairment [8]. The management of BC patients requires a multidisciplinary approach $[5,9]$. In our hospital, almost all patients with $\mathrm{BC}$ are discussed, and an individual plan of treatment is presented for every single woman. Of course, the decision is made after acceptance by the patient. We believe that for every patient with cancer a proper therapy plan that is accepted by a patient can be prepared [10]. A review of databases

Table 4. Univariate Cox proportional-hazard regression analysis for disease-free and overall survival

\begin{tabular}{|c|c|c|c|c|c|}
\hline & \multirow[t]{2}{*}{ Factor } & \multicolumn{2}{|c|}{ Disease-free survival } & \multicolumn{2}{|c|}{ Overall survival } \\
\hline & & HR (95\% Cl) & $p$-value & HR $(95 \% \mathrm{Cl})$ & $p$-value \\
\hline 1 & Age $(<80$ vs. $\leq 80)$ & $1.7(0.4-6.2)$ & 0.4567 & $1.6(0.8-3.2)$ & 0.1817 \\
\hline 2 & Grading (1.2.3) & $6.9(2.2-21.2)$ & 0.0009 & $2.1(1.3-3.5)$ & 0.0500 \\
\hline 3 & Ki67 (< = 21 vs. $>21)$ & $5.9(1.5-23.7)$ & 0.0122 & $1.9(0.9-3.9)$ & 0.0699 \\
\hline 4 & Clinical stage $(0, \mathrm{I}, \mathrm{II}, \mathrm{III})$ & $4.7(1.5-14.8)$ & 0.0094 & $3.5(1.9-6.3)$ & 0.0001 \\
\hline 5 & Radical mastectomy (0.1) & Very high values & 0.9627 & $0.2(0.1-0.6)$ & 0.0058 \\
\hline 6 & Breast-conserving treatment (0.1) & $6.9(0.9-55.9)$ & 0.0667 & $5.9(2.1-16.7)$ & 0.0010 \\
\hline 7 & Simple mastectomy (0.1) & $1.2(0.1-9.2)$ & 0.8976 & $0.3(0.1-2.4)$ & 0.2759 \\
\hline 8 & Sentinel lymph node biopsy (0.1) & $0.2(0.02-1.2)$ & 0.0722 & $0.2(0.1-0.5)$ & 0.0013 \\
\hline 9 & Axillary dissection (0.1) & $6.5(0.8-51.9)$ & 0.0777 & $5.4(1.9-15.3)$ & 0.0017 \\
\hline 10 & Neoadjuvant chemotherapy (0.1) & $3.0(0.6-14.9)$ & 0.1809 & $3.7(1.6-8.7)$ & 0.0031 \\
\hline 11 & Adjuvant chemotherapy (0.1) & $1.1(0.2-5.1)$ & 0.9393 & $1.0(0.4-2.1)$ & 0.9339 \\
\hline 12 & Hormonotherapy (0.1) & $0.1(0.01-0.3)$ & 0.0002 & $0.2(0.1-0.5)$ & 0.0001 \\
\hline 13 & AntiHER2 therapy $(0.1)$ & Indeterminacy values & 0.9603 & $0.4(0.1-2.9)$ & 0.3641 \\
\hline 14 & Radiotherapy (0.1) & $0.8(0.2-3.2)$ & 0.7572 & $0.6(0.3-1.1)$ & 0.0936 \\
\hline
\end{tabular}


demonstrated that older women are more likely to have hormone receptor-positive and HER2-negative disease, which generally carries a more favourable prognosis. On the other hand, there is also evidence to support the hypothesis that $B C$ is more aggressive in older adults $[11,12]$. In our group, luminal subtypes of cancer were mostly represented, which can influence good early outcomes of the treatment. Despite advanced age, many women choose breast-conserving surgery, but in the analysed group, RM was mostly performed. The literature shows that BCS should always be considered in early cases of $B C$ [13-15]. When we look at the surgical procedures, its aggressiveness increased with the aggressiveness of cancer, and more radical mastectomies were performed in women with triple-negative or non-luminal cancer in comparison to patients with luminal subtypes. Mastectomy is often the only option of oncological treatment, especially in patients for whom systemic treatment or radiotherapy is contraindicated. An important factor deciding about the treatment and its outcomes is the status of regional lymph nodes [1]. In our group, in all women with invasive cancer and some with preinvasive ones, the estimation of regional lymph nodes was implemented. We avoided many unnecessary axillary dissections, replacing them with SLNB in patients without clinical evidence of regional lymph node metastases. Surgery with adjuvant hormonotherapy and radiotherapy were most often used. We did not observe any complications because of the usage of hormonotherapy and radiotherapy. Some authors presented evidence that these two methods of treatment are well tolerated and accepted by patients $[16,17]$. In our group, $100 \%$ of patients after BCS were irradiated with hypofractionated regimens. All of them completed radiation without complications. There are literature data showing that in older patients radiotherapy can be omitted after BCS [13]. Kunkler et al. found no difference in survival at a median 5-year follow-up time despite a slightly higher rate of locoregional recurrence in the nonirradiated group [17]. Kinj et al. presented also outcomes of replacing a long course of irradiation by accelerated partial breast irradiation with one single fraction. They confirmed that this method is safe and well-tolerated [18]. But in our group, in women for whom the omission of radiotherapy was proposed, they decided to be irradiated. Available data on adjuvant chemotherapy for BC are limited but suggest that it can be of benefit for well-selected patients, although the risk of short- and long-term toxicity is significant [19-21]. The purpose of neoadjuvant or adjuvant chemotherapy is to decrease the risk of relapse and mortality from BC by treating micrometastatic disease. $A$ randomized study demonstrated equivalent efficacy in terms of relapse-free and overall survival whether the chemotherapy was given in a neoadjuvant or adjuvant fashion [22]. Adjuvant chemotherapy when indicated should not be withheld from older women with early BC due to age alone, and the choice of chemotherapeutic agent can be similar to that which would be used in younger adults. However, the clinician must be particularly attuned to potential toxicities and should develop an individualized plan with the patient to determine the likelihood of benefit given other risk factors. Older age has been shown to correlate with an increased likelihood of developing therapy-related cardiotoxicity, and this risk is compounded when trastuzumab is given with an anthracycline-containing regimen [23-25]. The decision to start chemotherapy alone or with trastuzumab is much more difficult. Advanced age and comorbidities require this decision to be carefully considered because it may cause cardiological and haematological complications. Therefore, the qualification of patients for chemotherapy in our hospital takes place after a cardiological consultation. The toxicity of this therapy is also monitored during systemic treatment, and in particular with trastuzumab therapy. In many cases, we decided to use epirubicin because it is less toxic and safer. Prophylactic granulocyte-stimulating growth factors were used where there was the risk of febrile neutropaenia. But generally, these factors should be routinely prescribed for women over the age of 65 years receiving regimens of combined systemic treatment. It is very important that each patient is treated by one doctor during systemic treatment. Breast cancer in older women is thought to have a good outcome compared with $\mathrm{BC}$ in younger patients, but the prognosis varies considerably depending on many factors. Most breast cancers in older women are identified at an early, treatable stage, and the majority of women diagnosed with early-stage BC enjoy prolonged DFS [26]. In our group of patients, outcomes are good, probably due to rules that were implemented as for younger women, but the limitation of the study is the short follow-up. Deaths not connected with cancer were more common, in comparison with other causes. Standard multidisciplinary treatment for BC prevents recurrence and metastasis and tends to extend breast CSS even in older patients [27].

\section{Conclusions}

Breast cancer is a major health problem in the geriatric population. The treatment approach to older women in good general status with locally advanced BC should be similar to that of younger women. A treatment plan consisting of surgery of the breast and axilla, radiation therapy if applicable, and systemic treatment where indicated should be always considered. A decision should be made by the $B C$ team according to the rules of the $\mathrm{BC}$ centre.

\section{Disclosure}

The authors report no conflict of interest. 


\section{References}

1. Sun SX, Hollenbeak CS, Leung AM. Deviation from the standard of care for early breast cancer in the elderly: what are the consequences? Ann Surg Oncol. 2015; 22: 2492-2499.

2. Vanni G, Materazzo M, Pellicciaro M, et al. Does age matter? Estimating risks of locoregional recurrence after breast-conservative surgery. In Vivo 2020; 34: 1125-1132.

3. Lodi M, Scheer L, Reix N, et al. Breast cancer in elderly women and altered clinico-pathological characteristics: a systematic review. Breast Cancer Res Treat 2017; 166: 657-668.

4. Van Leeuwen BL, Rosenkranz KM, Lei Feng L, et al. The Effect of undertreatment of breast cancer in women 80 years of age and older. Crit Rev Oncol Hematol 2011; 79: 315-20.

5. Kacaoz S, Korukluoglu B, Parlak O, et al. Comparison of clinicopathological features and treatments between pre- and postmenopausal female breast cancer patients - a retrospective study. Menopause Rev 2019; 18: 68-73

6. Tesarova P. Specific aspects of breast cancer therapy of elderly women. Biomed Res Int 2016; 2016: 1381695.

7. Hutchins LF, Unger JM, Crowley JJ, et al. Underrepresentation of patients 65 years of age or older in cancer-treatment trials. N Engl J Med 1999; 341: 2061-2067.

8. Decoster L, Van Puyvelde K, Mohile S, et al. Screening tools for multidimensional health problems warranting a geriatric assessment in older cancer patients: an update on SIOG recommendations. Ann Oncol 2015; 26: $288-300$

9. Le Saux O, Ripamonti B, Bruyas A, et al. Optimal management of breast cancer in the elderly patient: current perspectives. Clin Interv Aging 2015; 10: 157-174

10. Jolly TA, Williams GR, Bushan S, et al. Adjuvant treatment for older women with invasive breast cancer. Womens Health (Lond) 2016; 12: 129-145.

11. Diab SG, Elledge RM, Clark GM. Tumor characteristics and clinical outcome of elderly women with breast cancer. J Natl Cancer Inst 2000; 92: 550-556.

12. Durbecq V, Ameye L, Veys I, et al. A significant proportion of elderly patients develop hormone-dependent "luminal-B" tumours associated with aggressive characteristics. Crit Rev Oncol Hematol 2008; 67: 80-92.

13. Inoue $\mathrm{H}$, Hirano A, Ogura $\mathrm{K}$, et al. Breast-conserving surgery without radiation in elderly women with early breast cancer. Surg Oncol 2019; 31: $22-25$.

14. Buszek SM, Lin HY, Bedrosian I, et al. Lumpectomy plus hormone or radiation therapy alone for women aged 70 years or older with hormone receptor-positive early stage breast cancer in the modern era: an analysis of the national cancer database. Int J Radiat Oncol Biol Phys 2019; 105: 795-802

15. Nichol AM, Chan EK, Lucas S, et al. The use of hormone therapy alone versus hormone therapy and radiation therapy for breast cancer in elderly women: a population-based study. Int J Radiat Oncol Biol Phys 2017: 98: 829-839.

16. Desideri I, Salvestrini V, Livi L. Recent advances in de-intensification of radiotherapy in elderly cancer patients. F1000Res 2020; 9: PMC7255897.

17. Kunkler IH, Williams LJ, Jack WJ, et al. On behalf of the PIII. Breast-conserving surgery with or without irradiation in women aged 65 years or older with early breast cancer (PRIME II): a randomised controlled trial. Lancet Oncol 2015; 16: 266-273.

18. Kinj R, Chand ME, Gal J, et al. Five-year oncological outcome after a single fraction of accelerated partial breast irradiation in the elderly. Radiat Oncol 2019; 14: 234.

19. Pondé N, Dal Lago L, Azim HA Jr. Adjuvant chemotherapy in elderly patients with breast cancer: key challenges. Expert Rev Anticancer Ther 2016; 16: 661-671.

20. Kimmick G. Adjuvant chemotherapy for breast cancer in older women: emerging evidence to aid in decision making. Curr Treat Options Oncol 2011; 12: 286-301.

21. Hamelinck VC, Bastiaannet E, Pieterse AH, et al. A prospective comparison of younger and older patients' preferences for adjuvant chemotherapy and hormonal therapy in early breast cancer. Clin Breast Cancer 2016; 16: 379-388.
22. Rastogi P, Anderson SJ, Bear HD, et al. Preoperative chemotherapy: updates of National Surgical Adjuvant Breast and Bowel Project Protocols B-18 and B-27. J Clin Oncol 2008; 26: 778-785.

23. Tan-Chiu E, Yothers G, Romond E, et al. Assessment of cardiac dysfunction in a randomized trial comparing doxorubicin and cyclophosphamide followed by paclitaxel, with or without trastuzumab as adjuvant therapy in node-positive, human epidermal growth factor receptor 2-overexpressing breast cancer: NSABP B-31. J Clin Oncol. 2005; 23: 7811-7819.

24. Perez EA, Suman VJ, Davidson NE, et al. Cardiac safety analysis of doxorubicin and cyclophosphamide followed by paclitaxel with or without trastuzumab in the North Central Cancer Treatment Group N9831 adjuvant breast cancer trial. J Clin Oncol 2008; 26: 1231-1238.

25. Serrano C, Cortes J, De Mattos-Arruda L, et al. Trastuzumab-related cardiotoxicity in the elderly: a role for cardiovascular risk factors. Ann Oncol 2019; 30: 1178 .

26. Hwang ES, Lichtensztajn DY, Gomez SL, et al. Survival after lumpectomy and mastectomy for early stage invasive breast cancer: the effect of age and hormone receptor status. Cancer 2013; 119: 1402-1411.

27. Takuwa H, Wakako Tsuji W, Yotsumoto F. Overall survival of elderly patients with breast cancer is not related to breast-cancer specific survival: a single institution experience in Japan. Breast Dis 2018; 37: 177-183. 